\title{
Mapping meanings of corporate social responsibility - an Australian case study
}

Anne Elizabeth Fordham ${ }^{1 *}$ and Guy M. Robinson ${ }^{2}$

\begin{abstract}
Corporate Social Responsibility (CSR) is an evolving concept that reflects various views and approaches regarding corporate relationships with broader society. This study examines the meanings and values attached to CSR within the Australian resource sector where various interests shape the implementation of CSR programs. The study was based on in-depth interviews with industry practitioners, business leaders, environmental and social specialists, government representatives and community leaders, including representatives from Indigenous groups.

CSR was found to be a complex, multi-dimensional concept that was highly individualised with a variety of aspects highlighted during interviews. To make sense of this complexity, meanings of CSR were mapped according to Carroll's four dimensions, namely Corporate, Legal, Ethical, and Philanthropic. However, a further CSR dimension was also required to capture the full spectrum of meanings. Referred to as 'CSR interaction', this dimension focuses on CSR meanings that align with the concept of CSR creating social change and improving the dynamics between companies and local communities and stakeholders.

This study also identified some key social processes or drivers which helped explain how and why CSR meanings and approaches are adopted and delivered. These drivers also increased understanding of the wide diversity of CSR meanings and their distribution across the different stakeholder groups. Drivers included not only individual-level influences such as background, life experience, cultural and ethical values, but also broader influences such as organisational and institutional context. The implications of this for CSR practice were explored.

The study sought to provide guidance for developing a working definition of CSR within the given context, through identifying the key integral requirements for CSR incorporating different perspectives and interests. The intent is that this can help support evaluation of the future success of CSR programs within the Australian resource sector.
\end{abstract}

Keywords: Corporate social responsibility, Sustainable development, Resource development, Stakeholder engagement, Sociology, Community development, Ethics

\section{Introduction}

CSR is a concept that captures the responsibility of business to the environment, its stakeholders and to the broader society (Blowfield 2005). It can be applied as a theory, research agenda, corporate practice or even ideal (Bice 2011). It is an open concept that has changed and evolved in light of altered circumstances and changing expectations of society (Lee 2008). The concept began to emerge in the 1950's as a philosophy of business doing good for society, including incorporating notions of

\footnotetext{
* Correspondence: afordham@internode.on.net

${ }^{1}$ School of Natural and Built Environment, University of South Australia,

Adelaide, South Australia 5095, Australia

Full list of author information is available at the end of the article
}

corporate philanthropy (Bowen 1953). It then expanded in the 1960's to place broader expectations on companies in terms of wider social concerns (e.g. environment, human rights) as driven by social rights' agendas and legislative change (Carroll and Shabana 2010). However, it was not fully adopted as a business discourse and managerial strategy until the 1990's and 2000's, when there was a focus on business practice accounting for and meeting stakeholder needs (Bice 2015; Lee 2008).

In the 2000's, CSR was viewed as the critical linkage between business strategy and sustainable development (Steurer et al. 2005). This included companies utilising CSR to align with relevant international and industry standards (e.g. United Nations Development goals, United 
Nations Global Compact and International Financing Standards). Such a connection of CSR from the local to the global was most relevant to large-scale global companies which had high public profiles and were cognisant of the need to gain reputational currency through CSR. This also occurred during a period of greater scrutiny of companies through social media, improved communication and the exchange of knowledge and information (Allen and Craig 2016; McDonald 2011). In the past decade, with the emergence of critical global-scale challenges such as climate change, scholars are advocating that CSR needs to shift from a discretionary or voluntary activity to an immediate and integrated response thereby acknowledging the major role and impact of business (Allen and Craig 2016). Thus, today CSR involves a complex agenda including managing localised impacts, e.g. water and biodiversity impacts but also contributing to solving broader-scale issues such as national-level prosperity and international-scale problems including climate change.

In exploring CSR and its capacity to meet societal needs, including sustainability, Okoye (2009) describes CSR as a 'contested concept' which attracts continual debate and argument about its actual meaning. He discusses how this is similar to other broad concepts of importance in society such as democracy and sustainable development, which are also shaped by society's needs at the time.

For CSR, this contestation involves a range of viewpoints and interests including civil society, local community, managers, government, investors and consumers, thereby incorporating multiple and diverse agendas. CSR is relevant to many groups and organisations given the substantial impact of business activities on society, including on development trajectories and community-level outcomes within the vicinity of the development ${ }^{1}$ (Bendell 2010). Therefore, various stakeholders wish to engage in the CSR debate and influence the direction of corporations and how the resources generated from development are utilised. This includes stakeholders placing a higher level of responsibility on companies to go beyond legislative compliance to address broader society goals and objectives (Carroll 2016).

The study seeks to explore these issues through examining the key meanings that different agents and stakeholders place on CSR which act to guide CSR practice in the Australian context, including linkages to broader societal goals. Meanings in this context refer not only to guiding principles or values for CSR but also mechanisms, processes and outcomes which are perceived to be integral and important in defining CSR.

This research approach aims to provide new understanding of stakeholder theory, which is concerned with how stakeholder interests are incorporated into CSR. Following a corporate-centric view, the theory considers stakeholder interests to be incorporated into CSR by the decisions and actions of corporate managers, who identify which stakeholders are relevant and then decide on how their views and interests can be included (Steurer et al. 2005). In this study, stakeholders directly introduce a range of meanings into CSR based on their own socio-political views and ideological positions. This is consistent with models of stakeholder engagement in CSR where stakeholders become directly involved in company/CSR decision making and the outcomes generated (Fordham and Robinson 2018; Manetti 2011).

The study scope was based on a multi-level perspective of CSR, which can assist in understanding the drivers and mechanisms of CSR and how social change can be created (Aguilera et al. 2007). The multi-level perspective acknowledges that there are individual (e.g. personal), organisational (e.g. corporate) and institutional (e.g. regulatory) levels of influence over CSR (Aguinis and Glavas 2012). The initial focus is on the individual-level scale of CSR, i.e. how CSR is interpreted and delivered through key agents that are directly involved and engaged with CSR. CSR research has primarily focused on the organisational or institutional level rather than individual level of analysis (Aguinis and Glavas 2012). However, multi-level perspectives were also captured by examining the primary drivers occurring across a range of scales (e.g. background of individuals) (individual scale) (Hur et al. 2016), company culture (organisational scale) (Black 2006), which explain why specific values and issues are important.

A major challenge of this study was how to place and frame a complex array of CSR meanings and values to help interpret and understand CSR practices. To achieve this the study drew upon Carroll's four dimensions of CSR (corporate, ethical, legal, and philanthropic,) which together define CSR and have been empirically tested in various contexts (Carroll 2016). The framework also involves trade-offs and tensions between the different elements and a balancing of different aspects to define CSR. For example, the integration of ethical interests across the other dimensions is an important aspect of defining responsibility.

The study also provides an opportunity to test Carroll's framework empirically at the level of individual CSR practice across various company and stakeholder interests. This provides scope to examine whether the framework captures all the elements considered salient by CSR practitioners from diverse perspectives.

Given this, the goals of the study reported in this paper are as follows:

- To map the meanings of CSR across a range of agents (both within companies and externally) who are involved with CSR. This provides understanding of the dynamics and mechanisms 
of CSR, including its capacity to incorporate a range of societal values.

- To identify the principal drivers that explain why specific meanings of CSR are important, through drawing upon multi-level perspectives of CSR.

- To utilise these findings to derive practical and theoretical insights into CSR practices.

These goals were examined within the Australian context, specifically the resource sector where a wide range of stakeholders contributes towards and has an interest in CSR. This includes government agencies and statutory organisations, local communities, Indigenous ${ }^{2}$ groups, non-government organisations (NGO's) and business leaders. Their inclusion is facilitated by institutional arrangements such as regulatory and legal frameworks, company policies and active citizen/organisation participation in issues. ${ }^{3}$

\section{Developing a framework for mapping meanings of CSR}

As an over-arching CSR theory, Carroll's four-part definition of CSR (comprising economic, legal, ethical and philanthropic dimensions) provides the scaffolding for identifying and mapping meanings of CSR within the resource sector in Australia: 'The social responsibility of business encompasses the economic, legal, ethical, and discretionary [later referred to as philanthropic] expectations that society has of organizations at a given point in time' (synthesis of Carroll 1979, p. 500; 1991, p. 283).

The economic dimensions of CSR reflect a company's economic responsibilities to broader society including how the company ensures it has a viable business model (Carroll 2016). Following a minimalist economic approach, a relevant CSR meaning is 'shareholder value' or companies orientating themselves towards generating profits in order to meet shareholder and investor interests (Friedman, 1970). This can be associated with a view that corporations have steered CSR towards profit making and financial interests at the expense of impacted communities and the environment (Banerjee 2008).

The business case for CSR is a justification that involves a variety of company approaches which go beyond a shareholder value perspective (Boso et al. 2017; Carroll and Shabana 2010). This includes a 'shared value' approach to CSR to meet both business and local community interests, eliciting community cooperation and buy-in to company operations (Porter and Kramer 2006). Within this approach, business is considered to have the knowledge and resources to help solve 'problems' related to its expertise and business model and thus add value to society (Garriga and Melé 2004). Driven by a more altruistic business case is a corporate citizenship approach which aligns CSR to broader social, economic and environmental needs including no or limited direct business benefit to companies (Waddock 2008). This is typically seen in the case of globally-driven companies linked closely to industry/sustainability goals.

In operation of the business case, CSR can be regarded as an extension of corporate values including linking to broader industry mandates and wider stakeholder expectations (Basu and Palazzo 2008). This can include the creation of operating principles for CSR which guide how the organisation functions, including CSR policies which guide company operations (Bondy 2008).

Legislative dimensions of CSR involve establishing legal ground-rules under which corporations operate, capturing some minimum standards of practice (Carroll 2016). This includes abiding by national and state laws regarding operational practices, e.g. labour, Indigenous rights and environmental standards, while also voluntarily aligning to broader international/industry standards (Cramer 2005; Michell and McManus 2013). ${ }^{4}$ Regulatory frameworks can be considered integral to CSR as they influence company behaviour and the type of CSR delivered (Söderholm and Svahn 2015).

Ethical dimensions reflect an expectation that business behaves in a manner that is consistent with societal mores and ethical norms by going beyond legal compliance, including recognising and respecting new or evolving ethical norms (Garriga and Melé 2004). A key ethical aspect of CSR is stakeholder theory that espouses the requirement for a company to account for a range of stakeholder needs (Esteves and Barclay 2011). If business accepts this obligation the scope of CSR is expanded, for example the ISO on CSR contains a complex array of human rights, and social, environmental and community objectives albeit as a voluntary standard (Asif et al. 2013). However, the capacity for corporations to meet stakeholder requirements has been challenged, with examples provided of where stakeholders with little power, e.g. local communities, are not acknowledged and their interests are ignored by corporations ${ }^{5}$ (Gilberthorpe and Banks 2012).

In lieu of stakeholder theory, CSR 'meanings' incorporate broader ethical themes reflecting stakeholder perspectives, including linking CSR to sustainability and to human rights agendas. For sustainability, typically this includes following a triple bottom line approach, that is maximising or balancing economic, social and environmental contributions of the company (Dahlsrud 2008; Pesmatzoglou et al. 2014).

Human rights are also taken as a basis for CSR particularly in the global market place (Garriga and Melé 2004). Most relevant CSR strategies e.g. human rights policies as espoused by global companies, align with the Universal Declaration of Human Rights (United Nations General Assembly resolution 217a, 10 December 1948) 
and cover strategies such as civil and social rights and resolving community grievances. Finally, ethical CSR meanings can include companies behaving in an intrinsically moral fashion through a common good ethic, and showing the capacity to address wider society expectations and the general well-being of society (Garriga and Melé 2004).

Philanthropic dimensions of CSR capture voluntary or discretionary activity of giving back to society, i.e. businesses with the capacity to contribute financial, physical and human resources (Baden 2016; Carroll 2016; Masoud 2017). Philanthropic activities pursued by companies include gifts of monetary resources, product and service donations, volunteerism by employees and management, community development and any other discretionary contribution to the community or stakeholder groups comprising the community. Companies undertaking voluntary activities that contribute to society represent an integral aspect of CSR (Dahlsrud 2008) and this integrates with economic and ethical dimensions of CSR. This voluntary activity contributes to either creating benefits for the immediate locality or strategies that generate broader benefits to the region, state or nation (Söderholm and Svahn 2015).

\section{Methodology \\ Study scope}

To capture views of CSR across different contexts, the study included multiple jurisdictions in Australia, namely the Northern Territory, South Australia and Western Australia. These jurisdictions have different regulatory arrangements, legislative frameworks and resource mining sites with different environmental and social characteristics (Fig. 1). To gain broad representation of resource companies practicing CSR, twenty-five were selected based on stratified sampling involving company size, operational stages of development, commodity types (mining, oil and gas) and location including prominence within jurisdictions. Sites of resource development were located within rural contexts where rural is defined as non-metropolitan and is classified here according to the level of remoteness (Fig. 1). ${ }^{6}$ Resource companies were selected that possessed active CSR programs and interactions with either local communities or broader stakeholder groups.

Representatives of key stakeholders directly interacting with these companies were also interviewed. These included business consultants (engaged by companies to undertake CSR activities), NGO's (who work collaboratively with companies on CSR or have interests to do so), government (which regulates or participates in CSR processes), and communities (who are divested CSR activities or are impacted by CSR locally).

\section{Use of semi-structured interviews}

Interviewees within the participant groups were selected using non-probability-based purposive sampling in which key informants were approached on the basis of their relevance to the study, as detailed by Sarantakos (2005). Relevance meant that they either worked for one of the selected resource companies and their prime focus was on CSR or that they represented a stakeholder group involved in CSR at relevant sites. Stakeholders were selected who had expertise, leadership and knowledge across areas crucial to CSR, such as community consultation, economic and business development, environmental management, Indigenous affairs and social and human rights. As a result, community representatives were leaders within the community or for the other groups. Individuals selected held influential and/or leadership positions within the organisation.

Interviewees were selected using Snowball sampling (Vogt 1999), or sourced through referencing media sources, social media and consultation of lists of participating organisations in CSR. Snowball sampling is where interviewee participants identify further potential participants and, in this case, inform the researchers about existing and relevant stakeholders, i.e. stakeholders considered of importance within the given context or identifying company employees with specific interest and/or appropriate CSR roles.

This resulted in 28 resource company employees being interviewed across the 25 companies who engaged with CSR and communities across various work roles and levels of responsibility. In relation to stakeholders interviewed, this included 15 business consultants, 14 NGO's, 16 government employees, 20 local community leaders and 20 Indigenous owner groups, capturing stakeholder activity across various sites and contexts.

Semi-structured interviews were undertaken, with some key questions identified which were then pursued further with associated questions to enable clarification and further exploration. This included asking interview participants how they defined and understood CSR and what was important in relation to CSR practice. Secondly, they were asked to reflect on relevant CSR activities and processes with which they were involved or affected including describing the CSR outcomes. ${ }^{7}$ For stakeholders, this included reflecting on company performance from their own knowledge and experience, either about a single company or group of companies within their locality or a broad range of companies for those that worked at a regional, state or national level. They were also asked about the capacity for CSR to connect to wider community agendas. 


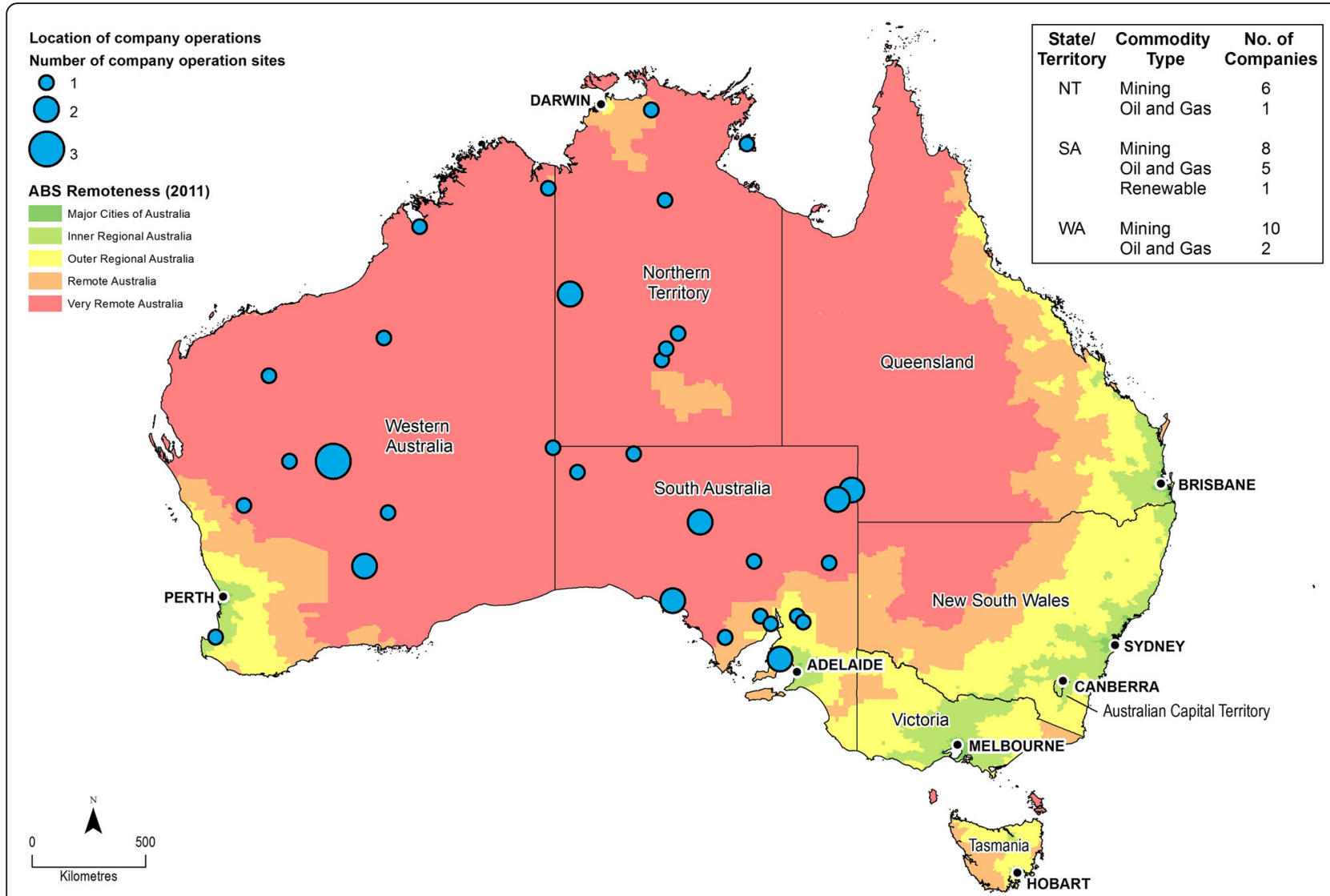

Fig. 1 Map of key sites of resource companies participating in the study. (Source: Prepared by Kate Rampellini, Curtin University, Perth, 2016)

\section{Mapping meanings of CSR}

The data were analysed using an abductive research technique based on a hierarchical theme-based coding technique (Lewins and Silver 2014). ${ }^{8}$ An initial hierarchy, including categories, themes and sub-themes initially comprised Carroll's four dimensions of CSR with relevant CSR themes grouped under these in a hierarchy (see Section "Developing a Framework for Mapping Meanings of CSR"). ${ }^{9}$ This hierarchical framework then provided the initial guidance/template for theme-based coding of the transcript material.

Consistent with an abductive research technique, new CSR themes were also identified during coding. The criterion for determining a new theme was that it was identified by an interviewee as being critical and integral to their interpretation of CSR or it was a strong and recurrent theme emerging from CSR practitioners' discussions of how CSR was implemented. ${ }^{10}$ The identified CSR meanings reflected individual/personal meanings/ views of CSR, although these were often aligned with broader organisational values. The requirement to code new themes led to the need to develop a new dimension or category of CSR, which was unrelated to Carroll's four dimensions and was called 'CSR interaction', with six themes coded underneath this category.

The theme-based coding was conducted through Max-QDA (Verbi 2015) where categories, codes and sub-codes were constructed and transcripts coded to these. From this various themes and reports were generated including the analysis of the frequency of themes across and within transcripts according to a range of variables. The latter included gender, culture, locality and the participant's stakeholder group. These reports enabled analysis of statistical differences between stakeholder groups in terms of CSR meanings.

Given the large number of CSR meanings identified through the coding, including multiple meanings within a single interview, initial themes coded for each participant were downloaded into an Excel spreadsheet and ranked. The ranking involved evaluating the relative weighting or importance given to a specific CSR meaning including consideration of the following:

- Was the CSR meaning identified initially when participants were asked to define CSR? These CSR meanings were given higher preference than those 
identified through interviewees' discussion of their experiences of implementing CSR.

- How often was the CSR meaning mentioned by the participant during the interview? Meanings that were consistently referred to and emphasized as important gained a higher ranking.

- How important was the CSR meaning to the overall approach to CSR? A CSR meaning which was only a small component of a CSR approach (lower on the hierarchy), tended to attract a lower ranking.

This analysis enabled further examination of variables impacting on CSR meanings, for example, focusing on the top five CSR meanings across different stakeholder groups.

The key meanings that were considered integral to CSR in this context were identified, i.e. those themes considered by a significant number of participants ${ }^{11}$ to be essential for implementing CSR within the context of the Australian resource industry. As such the definition has validity within the specific context of the study, i.e. the resource sector in rural and remote communities within Australia.

\section{Results and discussion Overview}

A wide range of CSR meanings were mapped $(n=38)$ across the dimensions of CSR, consistent with the idea that CSR is contested, variable in nature and integrates societal values and interests ${ }^{12}$ (Tables 1 and 2).

There was large variation in the expression of these meanings across participants, including which were high priority meanings. Each participant had a multi-dimensional perspective of CSR, which involved integrating different CSR themes in a unique way. ${ }^{13}$ This indicates that individual-level influences are important in determining how CSR ideologies are combined to form CSR approaches. Drivers helped explain this diversity including not only those at an individual level but also those related to organisational or broader institutional influences (see Section "Working Definition of CSR"). Diversity was also created because, according to the study participants, there was no institutional mechanism or frameworks available for them to decide collectively on what CSR means. ${ }^{14}$

\section{Mapping themes against the key dimensions of CSR Economic dimension of CSR}

The economic dimension directed CSR towards meeting corporate and economic agendas, ${ }^{15}$ particularly for company employees. That is, the economic dimension aligned CSR with various business approaches, thereby providing employees and, to a lesser extent, external stakeholders with guidance for CSR. For example, 75\% of company employees had at least one business case approach within their top five CSR themes, going beyond purely focusing on shareholder value. This contrasts to findings in Ghana where shareholder value was a key driver of CSR for company managers (Boso et al. 2017).

The most important business case identified was incorporating social license ${ }^{16}$ interests into CSR $(82 \%$ employees, $46 \%$ of employees in top five meanings). Social license means local communities and stakeholders approve of companies operating within their locality and either do not hinder their activities or actively support them (Boutilier and Thomson 2011). In this context, social license meant CSR services local and regional communities impacted by development, including direct engagement with communities, e.g. via face-to-face interaction (grass-roots approach) and developing collaborative CSR strategies to meet community needs consistent with the findings of Boso et al. (2017). However, companies may focus social license interests on short-term community needs or supporting the immediate interests of certain community members (Bice 2014). ${ }^{17}$ The economic dimension also included business-case approaches that went beyond social license, including expressing corporate values (43\%) or involving a shared-value approach (46\%). These provide a more complex approach to CSR and broaden its scope by facilitating a greater range of ethical and philanthropic meanings.

This dimension also contained company processes which provided a framework for CSR and had relevance for all stakeholder groups. The most important was identifying and mitigating risks (social, environmental, economic) and improving opportunities from resource development. Within this, external stakeholders typically had broader definitions of risk than company employees, integrating aspects such as cumulative-level impacts, land-use conflicts and identifying social and human rights impacts. They also looked to align the opportunities from resource development to local needs, including strategies which support community livelihoods and ongoing community viability.

The need to have robust CSR policies in place to guide company practice and enable transparency was also a major theme found in the economic dimension. According to participants (NGO's, Indigenous leaders, company employees) this helped facilitate sufficient structure, transparency and accountability around CSR. ${ }^{18}$ Robust CSR policy can reduce the possibility that corporate rhetoric at company headquarters is not translated to the site-level (Bice 2015). In this study resource companies deploying such policy frameworks were medium- to large-sized companies, with their CSR employees describing how they designed and deployed policy across the organisation. 
Table 1 Key Meanings of CSR that have been mapped in this study (Meanings in italics are derived specifically from the resource industry)

\begin{tabular}{|c|c|c|}
\hline $\begin{array}{l}\text { Carroll's } \\
\text { CSR Dimensions }\end{array}$ & Definition & Key CSR Themes \\
\hline Economic & $\begin{array}{l}\text { Reflect business approaches to CSR } \\
\text { consistent with company values and } \\
\text { need to retain a business case for CSR. } \\
\text { This includes facilitating indirect and } \\
\text { direct economic benefit. }\end{array}$ & $\begin{array}{l}\text { - Create Shareholder Value- Maximising profit and benefits for shareholders } \\
\text { (Freeman 1984). } \\
\text { - Business Case for CSR-Creating a business rationale for CSR aligned to } \\
\text { corporate values (Carroll and Shabana 2010). } \\
\text { - Create Shared Value- Providing mutual community and company benefit } \\
\text { through CSR (Porter and Kramer 2006). } \\
\text { - Corporate Citizenship Approach- Aligning CSR to broader society goals } \\
\text { without direct business benefit (Waddock 2008). } \\
\text { - Company Values- CSR as an expression of company values } \\
\text { (Carroll and Shabana 2010). } \\
\text { - Social License to Operate- The need to gain local community acceptance for } \\
\text { company operations (Esteves 2008). } \\
\text { - Identify Risk Versus Opportunities- Identifying and mitigating risk and } \\
\text { enhancing the opportunities of resource development (Gamu et al. 2015). } \\
\text { - CSR Policy- Developing clear corporate policy on CSR and operationalising this } \\
\text { as part of a business case for CSR (Aguilera et al. 2007). }\end{array}$ \\
\hline
\end{tabular}

Legal Reflect legal instruments that influence and shape CSR that are external to the corporation.

Ethical
Reflect ethical considerations that companies need to consider in order to meet stakeholder and broader society expectations.
- Regulatory Frameworks- Government regulatory frameworks regarding allowing resource development and the level of acceptable risk including on environment and on impacted communities (Michell and McManus 2013).

- Native Title Legislation- Affords Indigenous people rights to say no or negotiate with resource development and receive compensation for impacts (O'Faircheallaigh 2008)

- Agreement Making: The legal agreement made between resource company and Indigenous group with land claim (O'Faircheallaigh 2008).

- International Standards: Typically voluntary either industry-based or wider international frameworks around sustainable development or human rights (Cramer 2005).

- International Mineral Council: Ten principles of sustainable development (ICMM 2014).

- Sustainable Development: Link CSR to the creation of broader sustainable development outcomes

- Triple Bottom Line: Balance economic, environmental and social interests (Dahlsrud 2008).

- Weak Sustainability: Where assets from resource development are converted into other community capitals (Davies et al. 2012)

- Create Long-Term Value: Create long-term benefit for local communities based around building community-based assets (Fordham et al. 2017).

- Sustainable Livelihoods: Create community livelihoods that can last post-resource development (Fordham et al. 2017).

- Strong Sustainability: Where irreplaceable assets are protected from the impacts of resource development (Moran et al. 2013).

- Environmental Protection and Rehabilitation: Protect the environment and where practical rehabilitate it or off-set development impacts.

- Mine-site Rehabilitation: Ensure that mine-site is rehabilitated including aesthetics but also to reduce deleterious off-site impacts (Lamb et al. 2015).

- Cumulative Impacts: Address the cumulative impacts of resource extraction such as impacts on water, biodiversity and also social/economic impacts (Franks et al. 2010).

- Cultural Heritage: Protect the cultural heritage values of the landscape including sites of significance and dreaming trails.

- Climate Change: Address climate change through CSR activities, e.g. carbon capture strategies or reduce/mitigate carbon emissions (Allen and Craig 2016)

- Human Rights: Incorporate human rights considerations into CSR, typically aligned to Universal Declaration of Human Rights (Garriga and Melé 2004, International Organisation for Standardisation 2010).

- Rights of Local Communities: Consider rights of impacted communities including mitigating the negative, particularly human rights effects of resource development.

- Indigenous Rights: Incorporate Indigenous rights into CSR including policies such as reconciliation and improving key social and economic outcomes.

- Free Informed Prior Consent: Recognising the right for Indigenous autonomy and self determination: the legal right for local communities, particularly Indigenous communities, to say no to resource development (Owen and Kemp 2014). 
Table 2 Percentages of Participants in each group which adopted a specific CSR meaning

\begin{tabular}{|c|c|c|c|c|c|c|c|}
\hline & Res Com & Consul & NGO & Gov & Ind & Com & Tota \\
\hline & $N=28$ & $N=15$ & $N=14$ & $N=16$ & $N=20$ & $N=20$ & $\mathrm{~N}-1$ \\
\hline & $\%$ & $\%$ & $\%$ & $\%$ & $\%$ & $\%$ & $\%$ \\
\hline \multicolumn{8}{|l|}{ Economic } \\
\hline Business Case for CSR & 25 & 0 & 0 & 0 & 0 & 5 & 7 \\
\hline Shareholder Value & 11 & 33 & 29 & 19 & 5 & 10 & 16 \\
\hline Create Shared Value & 46 & 7 & 7 & 6 & 0 & 15 & 17 \\
\hline Corporate Citizen Approach & 0 & 0 & 7 & 0 & 0 & 0 & 1 \\
\hline Create Social license & 82 & 20 & 36 & 31 & 10 & 15 & 36 \\
\hline Apply Company Values & 43 & 0 & 0 & 0 & 0 & 0 & 11 \\
\hline Address Risks \& Opportunities & 43 & 33 & 57 & 50 & 15 & 75 & 45 \\
\hline CSR Policy Frameworks & 32 & 20 & 29 & 6 & 25 & 20 & 23 \\
\hline \multicolumn{8}{|l|}{ Legal } \\
\hline Regulatory Frameworks & 11 & 27 & 50 & 63 & 30 & 35 & 33 \\
\hline Agreement making & 4 & 33 & 7 & 19 & 45 & 5 & 18 \\
\hline International Standards & 11 & 13 & 21 & 0 & 0 & 0 & 7 \\
\hline Industry Standard & 18 & 13 & 0 & 6 & 0 & 0 & 7 \\
\hline Broad Government Policy Framework & 0 & 13 & 0 & 6 & 0 & 25 & 7 \\
\hline
\end{tabular}

Ethical

\begin{tabular}{|c|c|c|c|c|c|c|c|}
\hline \multicolumn{8}{|l|}{ Sustainable Development } \\
\hline Triple Bottom Line & 21 & 27 & 57 & 38 & 5 & 45 & 30 \\
\hline Weak Sustainability & 4 & 0 & 0 & 0 & 0 & 0 & 1 \\
\hline Create Long-Term Value & 89 & 93 & 57 & 31 & 70 & 70 & 71 \\
\hline Sustainable Livelihoods & 46 & 33 & 14 & 31 & 50 & 60 & 42 \\
\hline Economic Prosperity & 14 & 7 & 57 & 19 & 20 & 20 & 21 \\
\hline Strong Sustainability & 0 & 0 & 14 & 0 & 0 & 0 & 2 \\
\hline Environmental Protection and Rehab & 18 & 33 & 79 & 25 & 55 & 55 & 42 \\
\hline Mine-site Rehabilitation & 14 & 27 & 29 & 44 & 55 & 15 & 29 \\
\hline Cumulative Impact & 11 & 7 & 29 & 25 & 15 & 30 & 19 \\
\hline Cultural Heritage & 14 & 7 & 7 & 19 & 65 & 10 & 21 \\
\hline Climate Change & 4 & 0 & 43 & 13 & 0 & 0 & 8 \\
\hline Human Rights & 0 & 0 & 0 & 0 & 0 & 0 & 0 \\
\hline General Human Rights & 21 & 7 & 50 & 0 & 25 & 15 & 19 \\
\hline Indigenous Rights & 18 & 0 & 14 & 13 & 65 & 0 & 19 \\
\hline Free Informed Prior Consent (FIPC) & 11 & 20 & 21 & 6 & 20 & 15 & 15 \\
\hline Ethical Company & 39 & 53 & 64 & 25 & 50 & 70 & 50 \\
\hline \multicolumn{8}{|l|}{ Philanthropic } \\
\hline \multicolumn{8}{|l|}{ Community Development } \\
\hline Community Development & 29 & 60 & 14 & 13 & 85 & 10 & 35 \\
\hline Community Viability & 4 & 7 & 0 & 0 & 0 & 65 & 13 \\
\hline Create a social change & 39 & 40 & 7 & 6 & 55 & 0 & 27 \\
\hline Embed company in community/environs & 50 & 27 & 7 & 19 & 0 & 55 & 29 \\
\hline Business Development/Employment & 57 & 47 & 14 & 44 & 55 & 70 & 50 \\
\hline Education & 43 & 27 & 0 & 13 & 65 & 30 & 33 \\
\hline Economic Development & 14 & 20 & 14 & 50 & 60 & 60 & 36 \\
\hline
\end{tabular}


Table 2 Percentages of Participants in each group which adopted a specific CSR meaning (Continued)

\begin{tabular}{|c|c|c|c|c|c|c|c|}
\hline & Res Com & Consul & NGO & Gov & Ind & Com & Total \\
\hline & $N=28$ & $N=15$ & $N=14$ & $N=16$ & $N=20$ & $N=20$ & $\mathrm{~N}-113$ \\
\hline & $\%$ & $\%$ & $\%$ & $\%$ & $\%$ & $\%$ & $\%$ \\
\hline Strategic CSR & 39 & 13 & 36 & 13 & 0 & 15 & 20 \\
\hline \multicolumn{8}{|l|}{ Interaction } \\
\hline Empowerment and Self-Determination & 32 & 40 & 7 & 0 & 80 & 5 & 29 \\
\hline Engagement \& Communication & 64 & 67 & 64 & 88 & 50 & 80 & 68 \\
\hline Collaboration & 50 & 53 & 29 & 19 & 40 & 50 & 42 \\
\hline Relationship Building and Trust & 43 & 40 & 14 & 19 & 45 & 30 & 34 \\
\hline Accountability & 4 & 53 & 64 & 50 & 50 & 30 & 37 \\
\hline Innovation & 21 & 40 & 21 & 13 & 30 & 5 & 21 \\
\hline
\end{tabular}

Res Com resource company employees, Consul consultants, Gov government employees, Ind Indigenous, Com community members

development process and focus on environmental risk mitigation and protection, but there is an increasing emphasis on sustainable development and the need to engage and consult with communities (Government of South Australia 2014; EPA South Australia 2018).

In relation to CSR involving land with Indigenous interests, legal rights given to Indigenous people through land ownership or proving cultural connection to land ${ }^{23}$ were critical to CSR, particularly for Indigenous leaders who are afforded the legal privileges ${ }^{24}$ and their direct supporters (key business consultants, government statutory bodies). These legal interests enable Indigenous communities to derive direct financial benefits from CSR which can be instrumental in creating long-term community benefits (Fordham et al. 2018). This includes providing these communities with a mechanism to engage and become involved in CSR implementation including allowing them to hold companies to account.

Finally, regional government policy was viewed as an essential component of CSR by key local government, business consultant and local government and community representatives. This enables CSR to be addressed within a broader regional context, including tackling potential conflicts in land use and ensuring that regions can adapt to the impacts of resource development. However, the general sentiment was that government frameworks were currently inadequate to address the challenges of competing land uses.

\section{Ethical dimension of CSR}

The ethical dimension of CSR was found to be of primary importance in shaping CSR, thereby confirming the findings of Carroll (2016). This also reflects the implementation of CSR within a developed country context where legal frameworks and stakeholder needs help ground ethical values within CSR (Masoud 2017). This connected CSR to wider society concerns relating to sustainability and human rights discourses and it also accorded strongly with personal ethical values which included place/locality/community attachment. ${ }^{25}$ Ethical values were prominent across all stakeholder groups and were equally as significant for company employees as other stakeholder groups. However, external stakeholders introduced a wider set of ethical values into CSR. For example, NGO's introduced climate change and human rights ethics; Indigenous leaders cultural heritage protection; government and Indigenous leaders the need to restore mine-sites, and non-Indigenous communities stressed the need for ethical behaviour by companies.

The most common ethical value related to a weak sustainability approach, which allows the conversion of key capitals/assets from one form to another including natural capital to other forms of capital (Coulson et al. 2015). In this context this involves the conversion of key assets such as mineral and natural resources into other asset types, e.g. financial, human, social, built and other forms of natural asset (Davies et al. 2012). This was expressed through the notion of creating enduring value, that is ensuring something tangible and lasting is created by resource development. ${ }^{26}$ This meaning resonated across all stakeholder groups and was particularly important for company employees (89\%) and for locally impacted communities (70\%). Such a value was expressed by a range of philanthropic approaches and, as shown by Fordham et al. (2018), can lead to considerable community benefits when it is utilised to guide CSR implementation.

External stakeholders also emphasized 'strong sustainability' perspectives in their meanings of CSR, that is the importance of protecting key natural assets from degradation, including NGO's, leaders, and government leaders. For example, preventing the loss of irreplaceable natural assets through addressing cumulative-scale impacts, ${ }^{27}$ ensuring adequate mine-site rehabilitation ${ }^{28}$ and seeking to protect other productive land-use types such as agricultural lands. 
Incorporating human rights aspects into CSR, e.g. protecting Indigenous interests and rights, was seen as an essential CSR requirement for key external stakeholders (NGOs, business consultants, company employees) with human rights expertise, or for community leaders who were prepared to assert their own rights, e.g. $65 \%$ of Indigenous leaders described CSR approaches which involved the assertion and recognition of Indigenous rights.

For a small group of participants, the human rights value of Free and Informed Prior Consent (FIPC), that is, communities having the right to say 'no' to development, was considered integral to CSR. At a company level this included employees whose companies had adopted FIPC as an operating principle or employees who believed it was essential to social license. In the case of external stakeholders, it was pertinent for those from strong human rights backgrounds or those representing and looking to protect Indigenous interests within resource development. ${ }^{29}$ FIPC acknowledges that resource development has profound and often deleterious impacts on Indigenous people (Owen and Kemp 2014; Oxfam 2015).

\section{Philanthropic dimension of CSR}

The philanthropic dimension of $\mathrm{CSR}^{30}$ was primarily orientated towards providing benefit to local and regional communities through community development approaches and via strategic environmental and social programs. The concept of CSR facilitating community development was strongly held by Indigenous leaders (85\%) and business consultants $(60 \%)$ but less so by company employees (29\%). This dimension requires strong engagement with communities to understand their needs and preferences and to improve community empowerment through participation in CSR (Kemp and Owen 2013). The main focus of a community development approach was also different between Indigenous and Non-Indigenous communities interviewed. In the case of Indigenous communities the focus was on creating a social change to communities to lift their socio-economic circumstances including the importance of education (55\%). Whereas for locally-based communities it involved maintaining community viability despite rural decline and was exemplified by initiatives to generate income and prosperity (65\%). Specific CSR strategies were also highlighted that contribute to a community development focus involving education and skills development, employment and business development. ${ }^{31}$

Ensuring strategic CSR to achieve environmental and social objectives was also a key philanthropic approach (20\% coded themes). This was primarily driven by stakeholder involvement in CSR (NGO, government, community leaders), typically through collaborative CSR strategies with companies. Strategic CSR approaches were adopted by companies possessing corporate values contributing to wider society and connected to broader stakeholder and community processes. Typically, these were resource companies that are medium to large in size and possess a substantial degree of CSR capacity. These approaches are important for maximising the benefits of resource development and mitigating against negative impacts, as they contribute to landscape-scale benefit and/or address important social issues within the locality (Eberhard et al. 2013).

Finally, for companies to support philanthropic aspects at a local level, a major CSR approach involved companies becoming an integral part of the community (e.g. 50\% company employees). The employees and stakeholders supporting this view were those well-grounded in the locality, that is living amidst local communities and closely connected to community issues. This resonated well with local community leaders, e.g. CEO's of local government bodies.

\section{A new dimension of CSR: CSR interaction}

A new CSR dimension called CSR interaction was also identified through the coding which was in addition to Carroll's four dimensions of CSR. This captured CSR approaches relating to interpersonal ${ }^{32}$ behaviours which acknowledged the need to share power across CSR and facilitate new approaches and institutional frameworks. This supports the ideal of CSR as a social change mechanism as suggested by Gond and Matten (2010). Integral to this was how companies and stakeholders interact through CSR, including two-way communication, engagement and consultation between stakeholders and companies (68\% participants). This extends CSR to involving stakeholders in an active and meaningful manner, including involving them in decision-making (Moratis and Brandt 2017). Closely aligned to this was the need for relationship building and trust within CSR, with this being viewed by many as a precursor for implementing CSR, consistent with the findings of an allied study of the oil and gas industry in Queensland (Walton et al. 2017). Participatory approaches to CSR were also highlighted as necessary to CSR and extended to the use of multi-stakeholder forums on CSR. This mirrors international studies which show the importance of multi-stakeholder collaborations for state, company and civil society to achieve CSR and link companies to community livelihoods (Buitrago-Franco and Ali 2017).

This dimension also included the need to incorporate mechanisms of accountability ${ }^{33}$ into CSR to facilitate the required outcomes. This mirrors broader debates occurring regarding the need for greater levels of transparency and accountability through corporate 
practice, such as aligning corporations to initiatives like the Extractive Industries Transparency Initiative (EITI) (Pesmatzoglou et al. 2014). These views were held by stakeholders external to corporations including those impacted by resource development and those who are seeking to protect their interests and have the power to directly participate in CSR, e.g. NGO's (64\%), business consultants (53\%), government (50\%) and Indigenous leaders $(50 \%)$.

'Through CSR, you have to identify your impacts, disclose impacts and mitigate impacts' (NGO Representative). This approach was able to improve the quality of CSR outcomes, not only in terms of reducing the risks of resource development, e.g. environmental impacts, but also building positive community-based programs, e.g. business development (Fordham et al. 2018).

Harnessing of innovation for developing CSR practices was also recognised as important, e.g. the adoption of new technologies or new governance approaches, such as multi-stakeholder forums involving challenges to institutional norms. Innovation has been recognised as a critical aspect to facilitate development in regions that are resource rich as it can leverage human and economic resources to their best effect (Kinnear and Ogden 2014). This theme emerged through discussions across all stakeholder groups, but business consultants and Indigenous representatives had the highest ability to initiate innovative practices within CSR.

Finally, a significant element was to create empowerment and give self-determination to communities. The theme was highly significant for Indigenous people $(80 \%)$, and also for those working to represent their interests in CSR. However, these aspirations were generally only met in cases where significant resources and governance capacity are given through CSR, being primarily enabled through native title and company agreements with Indigenous communities. This CSR meaning aligns with recognised industry rhetoric and expectations of Indigenous academics seeking ways to improve development outcomes for Indigenous people (Langton 2014). However, broader research suggests these opportunities are unevenly distributed and rely on legal protections to give communities sufficient power (Langton 2014).

\section{Drivers impacting on the meanings of CSR}

In un-packing these CSR themes it is important to understand the specific social mechanisms enabling their adoption and impacting on how they are delivered within the specific context. Several drivers have been identified which help explain how and why CSR meanings/approaches were adopted and then delivered. These drivers also help explain and predict the reasons for the high diversity of meanings found across participant groups. However, it is clear that multiple drivers impact on a single CSR participant's understanding of CSR.

\section{Background and experience of the participant}

The background and experience of a CSR practitioner was a strong driver in influencing which meanings they attributed to CSR and how they delivered CSR in practice. During the interviews participants described how their own background and skill-set were instrumental to their understanding of CSR and the approaches taken. Participants effectively drew upon their own strengths and capabilities to operationalise $\mathrm{CSR}^{34}$ and were active in shaping CSR to their own preferences and directions.

The high diversity of backgrounds, skills-sets and educational profiles of CSR practitioners, both within ${ }^{35}$ and external to companies created diverse CSR meanings and approaches. External stakeholders, for example, were important in introducing new aspects and foci to CSR based on their specific skills, capability and background. For example, a group of anthropologists sought to ensure that the rights of Indigenous people were upheld and that company CSR resources were spent on genealogical research to provide the basis for a land rights claim.

Participants' approaches to CSR were affected by their life experiences, especially practical knowledge gained from working within the industry. This included experiences of difficulties in hosting resource development in remote regions. For example, a senior manager in the oil and gas industry experienced the death of a colleague in remote Australia from a heart attack. In response he steered the company's CSR program to incorporate a quick-response remote outback health service including access to a helicopter and four-wheel-drive service.

Participants also drew upon their experience of working within the industry and then applied this knowledge to developing regulatory frameworks. For example, a government employee directly experienced a major explosion on an oil and gas rig and consequently orientated his CSR approach around a strong risk and mitigation strategy which developed the capacity to influence regulatory frameworks for the oil and gas industry.

\section{Personal ethics values}

Personal ethical values were important for shaping the meanings of CSR that participants considered important and which shaped active participation in CSR. These personal ethics contributed to ethical meanings becoming cross-cutting themes across participant groups. For example, in the case of environmental values participants across different participant groups had genuine concern for the environment, including appreciating landscape values and natural systems. This meant that 
they emphasized environmental protection as a core aspect of CSR. This included those with a sense of place attachment, which affected how they responded to direct resource impacts within their locality, such as cumulative impacts on water resources or examples of poor mine-site rehabilitation. These ethics helped motivate some stakeholders to initiate or be involved in CSR programs such as landscape restoration and management, mine-site rehabilitation, and technological and engineering solutions to off-site impacts, e.g. wastewater recycling solutions.

Similarly, some participants had personal ethical values to improve the conditions of locally impacted communities, particularly those socio-economically disadvantaged by their remote location. This was motivated not only by genuine personal concern but also because of insight and capacity in how to improve communities' circumstances. In the case of key company employees, NGO's and business consultants this often involved applying an entrepreneurial approach, leading to these participants focusing on creating community development, social change, empowerment, and fostering business and employment opportunities. They took personal responsibility for designing CSR programs which bolstered community livelihoods and prospects, and they could challenge corporate practices. Company employees often regarded themselves as working for the community rather than the company. In one example, a community leader was concerned regarding his Indigenous community and its future prospects, so was active in developing a relationship with a local resource company to secure future business opportunities.

\section{Cultural background of participants}

The cultural background of participants influenced which CSR meanings were deemed important. This was most evident in the case of Indigenous people, who regardless of the participant group from which they originated, emphasized the need to embed cultural values into meanings and approaches to CSR. These were cultural heritage protection, environmental preservation and community development. Each Indigenous participant described CSR in relation to one or more of these cultural values, with CSR regarded as an opportunity to both protect and enhance these values. That is they possessed a personal responsibility to care for the land, its heritage and improve their own communities.

Aligning CSR strongly with cultural values also meant that they viewed CSR holistically, including looking at broad-scale collaborative solutions to address impacts and opportunities. For example, an Indigenous leader sought cooperation with other landowners and the resource company to improve management of a particular river catchment. They focused CSR on protecting certain values $^{36}$ rather than being orientated towards organisational agendas. This included possessing the capacity to identify new and innovative approaches to CSR, such as adopting new CSR policy frameworks:

'Imagine a company that goes in to create a mine. In the location, they know what the implications are for community so they apply the principle of social return on investment. So, if they have found a particular problem then their money would be contributing to improving the community life' (Indigenous community leader/business consultant).

By strongly aligning CSR to cultural values, Indigenous stakeholders could make significant personal commitments to CSR and strongly connect CSR to cultural outcomes of empowerment and self-determination. However, Indigenous leaders generally had insufficient power within the CSR space to put their ideas into practice except within their own sphere of CSR, as when CSR resources were directly divested to their communities through gaining legal rights.

\section{Organisational context}

Participants' meanings of CSR were shaped by their organisational setting, including the organisation's culture, values, structures and processes. Resource companies as primary host organisations for the delivery of CSR were shown to have significant influence over employees' meanings of CSR. Employees were required to align CSR to a corporate business case to justify their strategies. They were required to navigate between corporate demands/requirements and meeting broader society needs.

The alignment of CSR to social license arguments was a primary requirement and influenced the scope of CSR, including its spatial extent and the type of strategies supported. This determined which communities were targeted, with CSR being designed to meet the community's perceived needs. However, concepts such as shared value were also influential in the case of companies with more sophisticated approaches to CSR. For example, an employee of a gold-mining company used a shared-value approach as a guiding philosophy for developing his CSR programs across multiple sites:

'CSR is creating an enabling environment, a legacy focusing on the company's strengths and the community's interests' (resource employee, global resource company)

Company values were influential for companies where values were well-defined, typically pertaining to mediumto large-sized companies. For example, in the case of company employees situated within global companies 
where corporate values aligned with international objectives, this expanded the scope of CSR meanings, which involved broadening ethical aspects such as human and Indigenous rights. For example, six company employees with 15 or more meanings of CSR came from large-scale global companies. The importance of corporate influences for company employees was moderated by the impact of ethical and legal factors similar to discussions in Baden (2016). That is, company employees generally had a range of CSR themes across the five dimensions, unless the company's business model was very simplistic.

Interestingly, stakeholders viewed companies' business cases as largely motivated by an economic bottom line and they frequently portrayed a cynical, distrustful view of companies' 'morals', showing that in some contexts, the companies' social license was compromised. There were only a few select cases where stakeholders articulated more sophisticated business-models in their meanings of CSR, such as shared-value or corporate-citizen approaches (Table 2). This may represent a missed opportunity to understand and then work with corporate approaches to CSR. For example, despite the importance of social license to company employees, community leaders, including those from Indigenous groups, were largely unfamiliar or not conversant with the concept of social license. This supports other studies which found social license was of minimal relevance to communities (Lacey et al. 2012).

Stakeholder organisations were capable of influencing meanings of CSR but generally only in cases where they had clearly defined values and processes that informed approaches to CSR and possessed sufficient power to have influence over CSR. This included all the NGO organisations interviewed and some government organisations whose values provided guidance to CSR, e.g. over environmental and human rights approaches and standards. This was valuable as it helped introduce suitable frameworks and processes into CSR for resolving issues such as human rights, natural resource management, Indigenous reconciliation and FIPC.

\section{Institutional setting}

Generally, for participants embedded in large-scale organisations including companies and government agencies, CSR was focused on expressing organisational values and structured around developing related systems and processes, e.g. company policy/industry standards or key legislation. This reflects a command and control approach to CSR relying on policy frameworks and in some cases restricting the participant's ability to view CSR holistically and think beyond organisational mandates. Participants could become virtual agents of the organisation rather than thinking as individuals. In some cases this led to a narrowing of the definition of CSR and restricted the ability to apply flexibility, innovation and creativity within CSR. For example, government employees involved in regulation within a state government department focused CSR concepts on risk mitigation and found it difficult to conceptualise CSR as including positive opportunities from resource extraction. In the case of resource companies, this command and control approach could also restrict capacity for grass-roots activity and linking to local needs and aspirations. However, it could also create the capacity to deploy CSR approaches across a range of sites and contexts.

In contrast, for those participants in settings where there were no strong organisational values and guidance for CSR, meanings were moulded around personal understanding, insight and drawing upon professional standards and personal ethical values. Within this environment, participants, particularly business consultants and Indigenous leaders, demonstrated the capacity to develop new, innovative approaches to CSR and 'push the boundaries' by creating changes to existing institutional or organisational processes:

'CSR is about being entrepreneurial - that is "thinking outside the square" and developing innovative solutions that satisfy both parties' (business consultant).

This accords with the concept of individual agency introducing new opportunities into CSR (Painter-Morland and Ten Bos 2011).

\section{Working definition of CSR}

The aim of a working definition is to develop an agreed definition of CSR based on a range of employee and stakeholder needs for CSR. If this is conducted early in the resource development life-cycle it can improve the capacity to achieve long-term outcomes and satisfy local requirements. Critical to this is incorporating sufficient detail regarding mechanisms of accountability and transparency (Banerjee 2008), but not in a way that creates rigid views of CSR and prevents innovation and new approaches to CSR.

In order to develop a working definition of CSR here, key CSR meanings were identified which were considered by participants to be integral to achieving CSR. This incorporates different perspectives:

Economic: Align to an agreed business case (e.g. shared value, corporate citizen, value-driven), incorporate risk and opportunity (including stakeholder needs), formulate transparent CSR policy articulating the intent of CSR and how it will be delivered.

Legal: Identify and develop legal protection/mechanisms for environment, cultural heritage and Indigenous 
rights; support this with a specific agreement between company and community; draw upon/integrate CSR with broader international standards and guidelines.

Ethical: Create enduring community value for communities (according to community needs) including support for sustainable livelihoods; identify and protect prime natural assets including addressing issues such as cumulative impacts, mine-site rehabilitation; incorporate mechanisms which protect human and Indigenous rights; consider/acknowledge the validity of FIPC.

Philanthropic: Develop CSR from a community development approach, including integrating strategies such as education and skills development, employment, and business development. Facilitate this by integrating company within the wider community. Align where possible with broader strategic environmental, social and economic programs, and regional development needs.

CSR Interaction: Support CSR through two-way communication and engagement and where possible integrate stakeholders and communities into CSR decision-making; promote multi-stakeholder and broader participatory approaches to leverage greater value; acknowledge importance of relationship building and trust as basis for CSR; build in mechanisms of accountability and transparency; value innovation and creation of empowerment and self-determination through CSR.

Identifying these key criteria for CSR is also useful in helping communities and stakeholders to recognise current gaps in CSR programs and areas where they can advocate for more structure and direction with respect to CSR. These requirements can then provide guidance for formulating a detailed working definition ${ }^{37}$ which is mutually agreed between companies and stakeholders, with communities acknowledging that this may involve considerable debate and negotiation. However, by doing so, this improves accountability, transparency and defining mutual value and benefit within CSR. Furthermore, if working definitions were captured in a central repository they would form an interesting point of comparison regarding the scope of CSR and its capacity to meet defined requirements.

\section{Conclusion}

This study examined the concept of stakeholder theory in the Australian context where stakeholders held a range of values on and meanings of CSR that broadened its scope and potential capacity to meet societal interests. This included aligning CSR to ethical values such as sustainability (protection of key natural assets), Indigenous rights, and approaches to local communities and economic development. These values aligned CSR to critical environmental and social issues in government, business and community contexts, such as mine-site rehabilitation. Stakeholders also sought to embed higher levels of accountability within CSR practice. Company employees could be considered a form of 'stakeholder' capable of diffusing values and meanings based on their own ideologies, personal interests and experiences. This included shifting CSR past corporate economic interests to consider wider society mandates. The study also found cases where stakeholders, despite having legitimate claims, e.g. representing certain societal interests, were not able to engage or influence CSR due to a lack of power, resulting from the specific dynamics with companies and due to broader institutional influences.

The multi-level foci of the study, with a specific focus on individual perspectives, was found to be valuable for understanding the dynamics of CSR, including producing new perspectives on how CSR programs are formed and on relationships between ideologies and behaviours. CSR was found to be a multi-dimensional concept integrating various elements (across different dimensions) and capturing CSR values, approaches, processes and outcomes. These were highly individualised and diverse in nature, leading to different CSR meanings being captured. Many of these reflected different developmental stages of CSR, which continue to have relevance today. The focus on understanding individual perspectives on CSR also enabled significant drivers to be identified, which gave understanding to why specific CSR meanings were important and to the dynamics of how these were delivered. CSR was found to be a socially-driven phenomenon, highly influenced by participants' life experiences, background, culture and personal values but impacted by organisational and institutional arrangements.

In seeking to analyse CSR within the resource sector context, the study utilised Carroll's four dimensions of CSR as a framework to map CSR meanings. The framework was useful for identifying, mapping (including grouping hierarchically) and understanding the dynamics and interdependencies between the different meanings of CSR. This included for example, the importance of legal and economic approaches and frameworks enabling ethical values and philanthropic approaches to be introduced into CSR. The framework also clearly elucidated differences between company employees and different stakeholder groups in how they valued different aspects of CSR and the reasons for this. For example, legal frameworks were significant to Indigenous groups to protect their environmental and cultural interests.

The study enhanced the understanding of the scope of CSR by identifying an additional dimension, termed CSR interaction, needed to produce an overall model of CSR. The dimension emerged from understanding individuals' perspectives, including external stakeholders as well as company employees. The dimension was highly salient 
to defining responsibilities. It reflected opportunities and incorporated stakeholder needs and universal requirements, such as two-way communication and engagement. This dimension also reflected the need for CSR to create social change, challenge institutional arrangements and provide a basis for accountability, cooperation and power sharing between companies and the broader community and stakeholders.

\section{Practical implications}

This study provided a basis for developing a working definition of CSR in the Australian context by capturing various CSR elements that informed the implementation of practical CSR programs. This can be applied for planning of CSR, including developing approaches that facilitate cooperation and for design of evaluation tools to benchmark future performances. To date there have been few examples of where normative definitions of CSR have been made within a given context, including being based on multiple stakeholder views. ${ }^{38}$ The intent of this study was that by developing such a definition, this would also provide stimulus for discussion and resolution on what CSR means and involves, within a specific context. This should assist external stakeholders and communities to challenge corporations regarding the meaning and program directions of CSR in a specific context because they have a broader understanding of CSR.

From a pragmatic perspective, prior to instigating a CSR program involving diverse stakeholders and interests, it would be worth determining an understanding of perspectives and values regarding CSR. This would help to establish where joint programs could be developed with common values, even if parties possess disparate viewpoints. It may also reveal where stakeholders can introduce new values and meanings to CSR that could add value. There may be merit in developing a common agreed aspiration for CSR which can then help benchmark CSR performance, both at the program or project level but also potentially at local and regional scales.

The study also demonstrated at a practical level how CSR can operate at different scales and scopes beyond corporate practice. Overall, it was found that engaging a diverse array of company employees and stakeholders into CSR in varied institutional settings drove plurality in CSR practice, which extended the outcomes and linkage to societal benefit. Future management of CSR within the sector needs to seek to preserve this plurality while improving CSR practice through examining and learning from best practice at both company and broader institutional levels. This also needs consideration of the capacity and influence of each of the various stakeholders to make effective representation and ensure that key stakeholder interests are fairly and reasonably integrated within the working CSR program.

\section{Endnotes}

${ }^{1}$ This reflects the increasing power of corporations in society, including economic and political power.

${ }^{2}$ The term 'Indigenous' is used throughout this article to help communicate succinctly with this journal's audience. However, it is acknowledged that the correct and respectful term for Indigenous Australians is 'Aboriginal and Torres Strait Islanders' and no disrespect is meant through the use of 'Indigenous'.

${ }^{3}$ Thus, understanding CSR in this context requires the incorporation of government perspectives, corporate views from different company values and operational models, as well as the views of business and civil society groups and communities being impacted by or directly engaged with CSR.

${ }^{4}$ Government regulation seeks to protect the public/ government from having to pay costs for environmental damage and remediation. This is an externality that is generally not factored into economic markets (Aguilera et al. 2007).

${ }^{5}$ This can lead to the phenomenon of 'greenwashing, i.e. presenting positive CSR strategies to gain good publicity whilst masking poor underlying corporate practices which impact negatively on stakeholders (Watts 2005).

${ }^{6}$ The localities of resource development were classified by the Australian Standard Geographical Classification of Remoteness Areas (ASGC-RA) (Australian Bureau of Statistics, 2013). The ASGC-RA employs five categories: major cities, inner regional, outer regional, remote and very remote, utilising the 'level of remoteness' as a major approach to classify communities (Fig. 1). Remoteness considers distance and access to services as a key determinant, considering that these factors can be an impediment to community and economic wellbeing (Taylor, Carson, Ensign, Huskey, \& Rasmussen, 2016).

${ }^{7}$ When participants reflected on CSR processes they were better able to convey key CSR meanings of relevance to them.

${ }^{8}$ Theme-based coding involves identifying, pinpointing, examining and recording patterns (or "themes") within data. Themes are patterns across data sets that are important to the description of a phenomenon and are associated with a specific research question.

${ }^{9}$ This hierarchy comprised two levels: themes and sub-themes. Sub-themes were a sub-category or specific aspect of a broader theme. For example, a business case for CSR was a major theme but branched into sub-themes reflecting different CSR approaches to achieving a business case, e.g. social license to operate.

${ }^{10}$ For example, Indigenous interviewees consistently reflected on the importance of building relationships and trust for CSR when recalling their involvement and experience in CSR. 
${ }^{11}$ This includes considering views of both company employees and broader stakeholders.

${ }^{12}$ The number of CSR meanings ranged from five for the legal dimension through to fourteen for the ethical dimension.

${ }^{13}$ Participants' views on CSR included a blend of CSR meanings with synthesis across the five dimensions, and involving a combination of values, processes and outcomes.

${ }^{14}$ Multi-stakeholder forums were the key means through which views and perspectives on what CSR means within this context were discussed.

${ }^{15}$ The dimension comprised eight themes, $14 \%$ of overall themes coded and $14 \%$ of high priority themes.

${ }^{16}$ Communities of interest were defined on a company by company basis.

${ }^{17}$ See footnote 5 .

${ }^{18}$ Key stakeholders, such as Indigenous leaders, were also looking to improve the capacity of CSR policy frameworks to contribute to providing community benefits.

${ }^{19}$ The legal dimension comprised five CSR themes, with $6 \%$ of all themes coded to this dimension and $7.5 \%$ of high priority themes.

${ }^{20}$ In relation to industry standards at an international level, prominent mining companies align with the ten principles of sustainable development as set by the International Council on Mining and Metals (ICMM 2014). These companies are typically global players with significant market capitalisations. However, industry principles then cascade down to national-level industry approaches and so impact on a broader range of companies. Also, at a local level, jurisdictionally-based industry codes of practice provide guidance, including for small companies who do not have their own CSR policies and frameworks (Brereton 2002).

${ }^{21}$ Industry-led standards were highly meaningful for employees from multi-national, global companies seeking legitimacy and alignment with broader standards.

${ }^{22}$ For example, for Indigenous groups heritage legislation was critical to protect cultural heritage values through CSR.

${ }^{23}$ See O'Faircheallaigh 2008.

${ }^{24}$ This entitles them to legal compensation for resource development either through direct financial compensation or via specific agreements/commitments (O'Faircheallaigh 2004).

${ }^{25}$ The ethical dimension of CSR comprised 14 themes, accounting for $35 \%$ of themes coded and $36 \%$ of high priority themes.

${ }^{26}$ For example see, Minerals Council of Australia, 2015, Enduring Value - The Australian Minerals Industry Framework for Sustainable Development, https://www.minerals.org.au/enduring-value-framework. Accessed August 25th 2018.
${ }^{27}$ Refer to Franks et al. (2010) for cumulative impacts in Australia.

${ }^{28}$ To prevent long-term environmental impacts and mitigate the loss of environmental assets due to land clearance (Lamb et al. 2015).

${ }^{29}$ In the Australian context FIPC is implemented through legislation, notably for Indigenous people with land rights and/or global companies adhering to global standards.

${ }^{30}$ The philanthropic dimension consisted of seven elements with $22 \%$ of total CSR themes and $20 \%$ of high priority ranked themes.

${ }^{31}$ This is achieved through specific company programs, cooperative projects with community/stakeholders or by divesting resources to communities through community investment programs.

${ }^{32}$ This theme comprised $20 \%$ of total themes and $15 \%$ of high priority ones. From a company perspective these aspects helped to achieve a company business case and ensured that there was adequate engagement and consultation with stakeholders and the community regarding CSR. For stakeholders, the dimension defined their requirements for CSR via links to their personal and community aspirations.

${ }^{33}$ This included measuring CSR outcomes, monitoring environmental impact, having transparent CSR policies in place and aligning corporate policy to wider international mechanisms and standards.

${ }^{34}$ For participants with a business background, CSR was regarded as an opportunity to create economic development for communities, expressed through the creation of new enterprises.

${ }^{35}$ For example, a company employee with a social work background perceived CSR as a mechanism to address social issues, leading him to develop a prisoner rehabilitation program, rural employment adjustment program and mental health calendar as part of his CSR approach. In contrast, for an employee with a community development background, CSR meant ensuring communities could diversify away from mining, leading to the support of a broad range of community development initiatives.

${ }^{36}$ This was particularly the case for Indigenous leaders who were not highly institutionalised and therefore not beholden to organisational values.

${ }^{37}$ A working definition at a broader context could include: Companies or responsible entities develop transparent CSR policies articulating agreed values and approaches in connecting CSR to the specific context and creating value. This includes policies that address the risks and opportunities of resource development, include mechanisms of accountability inclusive of community and stakeholder input, and integrate with legislative requirements. CSR involves 
participatory approaches that can deliver long-term value to communities within the limits of available resources and it integrates community development principles with a focus on education and skills, employment, and business development. CSR is also related to strategic social and environmental programs through various regional processes.CSR is delivered through mechanisms of collaboration, with clear engagement, two-way communication and transparency in practice, facilitating relationship building and trust. Where possible innovation and new approaches to practice are incorporated including multi-stakeholder forums.

${ }^{38}$ The assumption is that a wide variety of stakeholders is important for protecting vital assets and interests in society.

\section{Abbreviations}

CSR: Corporate Social Responsibility; NGO: Non-Government Organisation; Social license: Social License to Operate

\section{Acknowledgements}

We would like to thank Dr. Boyd Blackwell, University of New England, and Dr. John Van Leeuwen, University of South Australia for their comments on the manuscript.

The work reported in this publication was supported by funding from the Australian Government Cooperative Research Centres Program through the Cooperative Research Centre for Remote Economic Participation (CRC-REP). The views expressed herein do not necessarily represent the views of the CRC-REP or Ninti One Limited or its participants (e.g. University of South Australia and University of New England).

\section{Funding}

This study was funded by the CRC of Remote Economic Participation (grant number H1.201).

\section{Availability of data and materials}

The data cannot be shared due to the ethics requirements which required that the data and its sources remain confidential.

\section{Authors' contributions}

AEF: Data collection, analysis, results, interpretation and preparing the first draft. GMR been involved in the research design and revising the document critically for important intellectual content and clarity of expression. Both authors read and approved the final manuscript.

\section{Ethics approval and consent to participate}

All procedures performed in studies involving human participants were in accordance with the ethical standards of the institutional and/or national research committee and with the 1964 Helsinki declaration and its later amendments or comparable ethical standards.

\section{Consent for publication}

Informed consent was obtained from all individual participants included in the study.

\section{Competing interests}

The authors declare that they have no competing interests.

\section{Publisher's Note}

Springer Nature remains neutral with regard to jurisdictional claims in published maps and institutional affiliations.

\section{Author details}

${ }^{1}$ School of Natural and Built Environment, University of South Australia, Adelaide, South Australia 5095, Australia. ${ }^{2}$ Department of Geography, Environment and Population, School of Social Sciences, University of Adelaide, Adelaide 5005, South Australia.
Received: 26 April 2018 Accepted: 6 August 2018

Published online: 18 September 2018

\section{References}

Aguilera, R. V., Rupp, D. E., Williams, C. A., \& Ganapathi, J. (2007). Putting the S back in corporate social responsibility: A multilevel theory of social change in organizations. The Academy of Management Review, 32(3), 836-863.

Aguinis, H., \& Glavas, A. (2012). What we know and don't know about corporate social responsibility a review and research agenda. Journal of Management, 38(4), 932-968

Allen, M. W., \& Craig, C. A. (2016). Rethinking corporate social responsibility in the age of climate change: A communication perspective. International Journal of Corporate Social Responsibility, 1(1), 1.

Asif, M., Searcy, C., Zutshi, A., \& Fisscher, O. A. M. (2013). An integrated management systems approach to corporate social responsibility. Journal of Cleaner Production, 56, 7-17.

Australian Bureau of Statistics. 2011. Australian Statistical Geography Standard: Remoteness Structure. Cat 1270.0.55.005.

Baden, D. (2016). A reconstruction of Carroll's pyramid of corporate social responsibility for the 21st century. International Journal of Corporate Social Responsibility, 1(1), 8.

Banerjee, S. B. (2008). Corporate social responsibility: The good, the bad and the ugly. Critical Sociology, 34(1), 51-79.

Basu, K., \& Palazzo, G. (2008). Corporate social responsibility: A process model of sensemaking. The Academy of Management Review, 33(1), 122-136.

Bendell, J. (2010). World review: July-September 2010. Journal of Corporate Citizenship, 40(6), 7-23.

Bice, S. (2014). What gives you a social Licence? An exploration of the social Licence to operate in the Australian mining industry. Resources, 3, 62-80.

Bice, S. (2015). Corporate social responsibility as institution: A social mechanisms framework. Journal of Business Ethics, 143(1), 1-18.

Bice, S. J. 2011. Beyond the business case: A new institutional analysis of corporate social responsibility in Australian mining, University of Melbourne, School of Social and Political Sciences.

Black, L. D. (2006). Corporate social responsibility as capability: The case of BHP Billiton. Journal of Corporate Citizenship, 23, 25-38.

Blowfield, M. (2005). Corporate social responsibility-the failing discipline and why it matters for international relations. International Relations, 19(2), 173-191.

Bondy, K. (2008). Institutions and agency in CSR strategy: An empirical investigation of development and implementation. Nottingham: University of Nottingham.

Boso, R. K., Afrane, S. K., \& Inkoom, D. K. B. (2017). Motivations for providing CSRmediated initiatives in mining communities of Ghana: A multiple-case study. International Journal of Corporate Social Responsibility, 2(1), 7.

Boutilier, R., \& Thomson, I. 2011. Modelling and measuring the social license to operate: Fruits of a dialogue between theory and practice. Retrieved from socialicense.com/publications website: http://socialicense.com/publications/ Modelling\%20and\%20Measuring\%20the\%20SLO.pdf.

Bowen, H. R. (1953). Social responsibilities and the businessman. New York: US, Harper.

Brereton, D. 2002. The role of self-regulation in improving corporate social performance: The case of the mining industry. Proceedings the current issues in regulation: Enforcement and compliance conference, Australian in-food safety and the role of the government: Implications for CSR policies in China.

Buitrago-Franco, I., \& Ali, S. (2017). Decentralization, corporate community development and resource governance: A comparative analysis of two mining regions in Colombia. The Extractive Industries and Society, 4(1), 111-119.

Carroll, A. B. (1979). A three-dimensional conceptual model of corporate performance. Academy of Management Review, 4(4), 497-505.

Carroll, A. B. (2016). Carroll's pyramid of CSR: Taking another look. International Journal of Corporate Social Responsibility, 1(1), 3.

Carroll, A. B., \& Shabana, K. M. (2010). The business case for corporate social responsibility: A review of concepts, research and practice. International Journal of Management Reviews, 12(1), 85-105.

Coulson, A. B., Adams, C. A., Nugent, M. N., \& Haynes, K. (2015). Exploring metaphors of capitals and the framing of multiple capitals: Challenges and opportunities for $<\mid R>$. Sustainability Accounting, Management and Policy Journal, 6(3), 290-314. 
Cramer, J. (2005). Applying international standards and guidelines on corporate social responsibility: An action plan. Environmental Quality Management, 14(3), 71-77.

Dahlsrud, A. (2008). How corporate social responsibility is defined: An analysis of 37 definitions. Corporate Social Responsibility and Environmental Management, 15(1), 1-13.

Davies, J., Maru, Y., \& May, T. (2012). Enduring community value from mining: conceptual framework: CRCRep Working Paper CW007. Alice Springs, Northern Territory: Ninti One Limited.

Eberhard, R., Johnston, N., \& Everingham, J. (2013). A collaborative approach to address the cumulative impacts of mine-water discharge: Negotiating a cross-sectoral waterway partnership in the Bowen Basin, Australia. Resources Policy, 38(4), 678-687.

EPA South Australia (2018). Public Register. https://www.epa.sa.gov.au/our_work/ public_register. Accessed August 25th 2018.

Esteves, A. M. (2008). Mining and social development: Refocusing community investment using multi-criteria decision analysis. Resources Policy, 33(1), 39-47.

Esteves, A. M., \& Barclay, M.-A. (2011). New approaches to evaluating the performance of corporate-community partnerships: A case study from the minerals sector. Journal of Business Ethics, 103(2), 189-202.

Fordham, A. E., \& Robinson, G. M. (2018). Mechanisms of change: Stakeholder engagement in the Australian resource sector through CSR. Corporate Social Responsibility and Environmental Management, 25(4), 674-689.

Fordham, A. E., Robinson, G. M., \& Blackwell, B. D. (2017). Corporate social responsibility in resource companies-Opportunities for developing positive benefits and lasting legacies. Resources Policy, 52, 366-376.

Fordham, A. E., Robinson, G. M., \& Van Leeuwen, J. (2018). Developing community based models of corporate social responsibility. The Extractive Industries and Society, 5(1), 131-143.

Franks, D. M., Brereton, D., \& Moran, C. J. (2010). Managing the cumulative impacts of coal mining on regional communities and environments in Australia. Impact Assessment and Project Appraisal, 28(4), 299-312.

Franks, D. M., Parra, C., \& Schleger, A. (2013). Approaches to understanding development outcomes from mining. London, UK: International Council of Mining and Metals (ICMM).

Freeman, R. E. (1984). Strategic management: A stakeholder approach. Boston: Pitman.

Friedman, M. (1970). The social responsibility of business is to increase its profits (pp. 122-124). New York Times Magazine, September 13.

Gamu, J., Le Billon, P., \& Spiegel, S. (2015). Extractive industries and poverty: A review of recent findings and linkage mechanisms. The Extractive Industries and Society, 2(1), 162-176.

Garriga, E., \& Melé, D. (2004). Corporate social responsibility theories: Mapping the territory. Journal of Business Ethics, 53(1-2), 51-71.

Gilberthorpe, E., \& Banks, G. (2012). Development on whose terms?: CSR discourse and social realities in Papua New Guinea's extractive industries sector. Resources Policy, 37(2), 185-193.

Gond, J.P., \& Matten, D. (2010). Rethinking the business-society Interface: Beyond the functionalist trap. Research paper series. Nottingham: University of Nottingham 47-2007.

Government of South Australia (2014). Legislation and Compliance: Environmental Register. Retrieved 13th September, 2016

Hur, W.-M., Kim, H., \& Jang, J. H. (2016). The role of gender differences in the impact of CSR perceptions on corporate marketing outcomes. Corporate Social Responsibility and Environmental Management, 23(6), 345-357.

International Council on Mining and Minerals (ICMM) 2010. ICCM 10 Principles. https://www.icmm.com/en-gb/about-us/member-commitments/icmm-10principles.

International Organisation for Standardisation 2010. License for ISO 26000 Guidance on CSR. https://www.iso.org/iso-26000-social-responsibility.html

Kemp, D., \& Owen, J. R. (2013). Community relations and mining: Core to business but not "core business". Resources Policy, 38(4), 523-531.

Kinnear, S., \& Ogden, I. (2014). Planning the innovation agenda for sustainable development in resource regions: A Central Queensland case study. Resources Policy, 39, 42-53.

Lacey, J., Parsons, R., \& Moffat, K. (2012). Exploring the concept of a social Licence to operate in the Australian minerals industry: Results from interviews with industry representatives. EP125553. Brisbane: CSIRO.
Lamb, D., Erskine, P. D., \& Fletcher, A. (2015). Widening gap between expectations and practice in Australian minesite rehabilitation. Ecological Management \& Restoration, 16(3), 186-195.

Langton, M. (2014). From conflict to co-operation: Transformations and challenges in the engagement between the Australian minerals industry and Australian indigenous peoples. Forest: ACT, Australian Minerals Council.

Lee, M. D. P. (2008). A review of the theories of corporate social responsibility: Its evolutionary path and the road ahead. International Journal of Management Reviews, 10(1), 53-73.

Lewins, A., \& Silver, C. (2014). Using software in qualitative analysis: A step-by-step guide. Los Angeles: Sage.

Manetti, G. (2011). The quality of stakeholder engagement in sustainability reporting: Empirical evidence and critical points. Corporate Social Responsibility and Environmental Management, 18(2), 110-122.

Masoud, N. (2017). How to win the battle of ideas in corporate social responsibility: The international pyramid model of CSR. International Journal of Corporate Social Responsibility, 2(1), 4.

McDonald, C. (2011). Social responsibility in the mining and metals sector in developing countries. Canberra: Australian Government.

Michell, G., \& McManus, P. (2013). Engaging communities for success: Social impact assessment and social licence to operate at Northparkes mines, NSW. Australian Geographer, 44(4), 435-459.

Moran, C., Franks, D., \& Sonter, L. (2013). Using the multiple capitals framework to connect indicators of regional cumulative impacts of mining and pastoralism in the Murray Darling Basin, Australia. Resources Policy, 38(4), 733-744.

Moratis, L., \& Brandt, S. (2017). Corporate stakeholder responsiveness? Exploring the state and quality of GRI-based stakeholder engagement disclosures of European firms. Corporate Social Responsibility and Environmental Management, 24(4), 312-325.

O'Faircheallaigh, C. (2008). Understanding corporate-Aboriginal agreements on mineral development. Earth Matters: Indigenous Peoples, the Extractive Industries and Corporate Social Responsibility, 1(20), 67-82.

O'Faircheallaigh, C. (2004). Evaluating agreements between Indigenous peoples and resource developers. In: M. Langton, L. Palmer, M. Tehan, and K. Shain (eds), Honour Among Nations?: Treaties and Agreements with Indigenous People. Melbourne: Melbourne University Press, pp. 303-323.

Okoye, A. (2009). Theorising corporate social responsibility as an essentially contested concept: Is a definition necessary? Journal of Business Ethics, 89(4), 613-627.

Owen, J. R., \& Kemp, D. (2012). Assets, Capitals, and Resources Frameworks for Corporate Community Development in Mining. Business \& Society, 51(3), 382-408.

Owen, J. R., \& Kemp, D. (2014). 'Free prior and informed consent', social complexity and the mining industry: Establishing a knowledge base. Resources Policy, 41, 91-100.

Oxfam. (2015). Community consent index: Oil, gas, and mining company public positions on free, prior, and informed consent 207 Oxfam briefing paper. Melbourne: Oxfam.

Painter-Morland, M., \& Ten Bos, R. (2011). Business ethics and continental philosophy. Cambridge: Cambridge University Press.

Pesmatzoglou, D., Nikolaou, I. E., Evangelinos, K. I., \& Allan, S. (2014). Extractive multinationals and corporate social responsibility: A commitment towards acheiving the goals of sustainable development or only a management strategy? Journal of International Development, 26(2), 187-206.

Porter, M. E., \& Kramer, M. R. (2006). The link between competitive advantage and corporate social responsibility. Harvard Business Review. 84(12), 78-92.

Sarantakos, S. (2005). Social research (3rd ed.). Basingstoke: Palgrave Macmillan Education.

Söderholm, P., \& Svahn, N. (2015). Mining, regional development and benefitsharing in developed countries. Resources Policy, 45, 78-91.

Steurer, R., Langer, M. E., Konrad, A., \& Martinuzzi, A. (2005). Corporations, stakeholders and sustainable development: A theoretical exploration of business-society relations. Journal of Business Ethics, 61(3), 263-281.

Taylor, A., Carson, D. B., Ensign, P. C., Huskey, L., \& Rasmussen, R. O. (2016). Settlements at the Edge: Remote Human Settlements in Developed Nations. Cheltenham: Edward Elgar Publishing.

Verbi. (2015). Max-QDA: The Art of Data Analysis. Berlin: Gmbh Standard 12.

Vogt, W. P. (1999). Dictionary of statistics and methodology: A nontechnical guide for the social sciences. London: Sage.

Waddock, S. (2008). The development of corporate responsibility/corporate citizenship. Organization Management Journal, 5(1), 29-39. 
Walton, A., Williams, R., \& Leonard, R. (2017). Community perspectives of coal seam gas development during two phases of industry activity: Construction and post-construction. Rural Society, 26(1), 85-101.

Walton, A. M., McCrea, R., Leonard, R., \& Williams, R. (2013). Resilience in a changing community landscape of coal seam gas: Chinchilla in Southern Queensland. Journal of Economic and Social Policy, 15(3), 2.

Watts, M. J. (2005). Righteous oil? Human rights, the oil complex, and corporate social responsibility. Annual Review of Environment and Resources, 30, 373-407.

Submit your manuscript to a SpringerOpen ${ }^{\circ}$ journal and benefit from:

- Convenient online submission

- Rigorous peer review

- Open access: articles freely available online

- High visibility within the field

- Retaining the copyright to your article

Submit your next manuscript at $\boldsymbol{\sim}$ springeropen.com 